\title{
PeÕes: Lula e A NOSTAlgia dA ClAsse OPERÁRIA
}

\author{
Marina Soler Jorge*
}

Consuelo Lins, no livro O Documentário de Eduardo Coutinho, considera Peões (Eduardo Coutinho, 2004) seu filme mais melancólico (Lins, 2004: 185). O próprio documentarista, no encarte do DVD de Peões, ao ser questionado se seu filme é melancólico, responde: "Existe ali, claramente, um tempo que terminou (...). Mas eu não tinha a intenção de fazer um filme melancólico". Efetivamente, penso que Coutinho está correto: seu filme, ao contrário do que considera Lins, não é melancólico. Não há uma idéia de tristeza pelo tempo que terminou ou de uma falta de entusiasmo que surgiria pela lembrança do passado. Peões é, na verdade, um filme nostálgico, no sentido de que nos passa antes a sensação da saudade do tempo que terminou do que de tristeza ou desânimo em relação a este. O interessante da nostalgia é que se trata de um sentimento de falta ou de saudade que não diminui na presença ou na lembrança dos fatos passados, ao contrário: aquele que sente nostalgia tem seu sentimento de saudade exacerbado e não diminuído quando entra em contato com aquilo que já passou. É isso que veremos no filme, na medida em que quanto mais se aproximam de seu passado, mais saudades dele parecem sentir os entrevistados. Temos a impressão de que aquelas memórias estavam inclusive como que adormecidas até Eduardo Coutinho

* Professora do Departamento de História da Arte - EFLCH/Unifesp. 
| 12 |

Peões: Lula e a nostalgia da classe operária

incentivar os ex-metalúrgicos a falar sobre elas. Quando lhes é dado a oportunidade de falar, os peões do título parecem abrir as portas não apenas de suas memórias, mas dos sentimentos nostálgicos que estas memórias despertam.

A nostalgia de Peões começa do começo: o começo do filme e o começo da história das greves de São Bernardo do Campo e Diadema. Eduardo Coutinho irá empreender uma busca pelo sertão do Brasil, nossa reserva de "brasilidade" como sugere Marcelo Ridenti (2000), para encontrar a origem do movimento classista dos anos 80. Lá, em Várzea Alegre, Ceará, ele encontrará antigos peões do ABC paulista que, depois de aposentados, conseguiram voltar à terra natal de maneira provavelmente muito melhor do que a deixaram décadas antes. Com efeito, todos os entrevistados que agora voltaram a viver no nordeste nos passam a sensação de que, apesar do trabalho na fábrica ter sido duro, foi esse trabalho que os tirou da situação de risco alimentar eminente na localidade de origem. Assim, o filme se inicia como se iniciou a trajetória de industrialização do $A B C$ paulista: com pequenos produtores rurais despossuídos que partem para São Paulo em busca de uma vida melhor. Essa trajetória, atestada pela História, é também a trajetória de Luís Inácio Lula da Silva. Sabemos que, como centenas de companheiros, sua família saiu do nordeste (Pernambuco) para tentar melhores condições de trabalho no estado de São Paulo. A trajetória de Lula, portanto, começa no ordinário, na estatística, como a trajetória típica da maior parte dos metalúrgicos do $A B C$. No entanto, do $A B C$ ela se transforma em uma trajetória absolutamente atípica. Do interior de Pernambuco para a direção do sindicato dos metalúrgicos, cargo de deputado federal e finalmente para a Presidência da República, temos a interferência do extraordinário. Em Entreatos (João Moreira Salles, 2004) Lula irá dizer que o que ocorreu com ele não está na sociologia. Realmente, não está. O que ocorreu com Lula foge do que se entende por uma trajetória típica a partir do momento em que o dirigente começa a ter a projeção nacional que o levaria finalmente à Presidência da República. 
Eduardo Coutinho, no entanto, vai atrás desta trajetória típica, tentando localizar participantes das greves de 79 e 80 que permaneceram anônimos. Sabemos que este cineasta tem, em seu cinema documental, uma preferência justamente pelos indivíduos comuns, cujas vidas estão escondidas na cotidianidade. O papel de Coutinho em seus documentários é justamente a de resgatar do completo anonimato esses indivíduos que nada parecem ter de extraordinário. Assim, o tema do filme, os peões que não se tornaram nem Presidentes da República nem ocuparam outros cargos eletivos importantes (prefeitos, deputados, etc), encontra lugar imediato no próprio estilo do cinema de Coutinho, que é por excelência, pelo menos até o momento, um cinema do homem comum. No entanto a comparação implícita com a trajetória de Lula reforça o caráter comum do homem comum pelo contraste óbvio que estabelece entre o banal e o extraordinário. Assim, a figura de Lula, que permanece como referência explícita ou implícita durante todo o filme, funciona em Peões numa dupla chave de leitura: Lula é ao mesmo tempo o exemplar da trajetória típica do migrante nordestino e o exemplar daquilo que, em certos momentos, ocorre de extraordinário na história política de um país. Nesse sentido, acredito que há em cada personagem de Peões um potencial Lula. Sabemos o que aconteceu a Lula e aos demais dirigentes que entraram para a política, mas não sabemos o que aconteceu com aqueles que permaneceram no anonimato. Apenas um entre tantos metalúrgicos, o Lula, se tornou o Lula, enquanto alguns poucos se tornaram prefeitos, deputados ou vereadores e a grande maioria não se destacou, permanecendo entre os anônimos que Coutinho quer resgatar do anonimato.

$\mathrm{Na}$ trajetória típica de migrante nordestino há, segundo Peões, um processo de tomada de consciência que aparece logo no início do filme na fala dos primeiros entrevistados em Várzea Alegre, Ceará. Essa tomada de consciência, da maneira como aparece no filme, não poderia ocorrer se aqueles homens e mulheres permanecessem no nordeste. Ao serem questionados se valeu a pena ir para São Paulo - afinal eles ao fim haviam voltado para o Ceará depois de se aposentarem - dois ex-metalúrgicos 
| 14 |

Peões: Lula e a nostalgia da classe operária

respondem que sim. Um deles, Bezerra, explica: ainda estaria votando em quem o coronel manda se não tivesse ido para São Paulo. Em outra entrevista o ex-metalúrgico Joaquim, este uma figura que nos parece extremamente simples, falará sobre a importância da orientação que os operários recebiam do sindicato e de Lula. Orientados, eles tinham força. Joaquim diz que não abandona São Bernardo jamais (sempre que pode pega um avião e volta para lá para ver seus filhos), pois foi lá que ocorreu tudo de importante na sua vida. Mais a frente no filme, outras entrevistas explicitam a importância que alguns entrevistados conferem ao fato de terem tido no sindicato em São Bernardo a oportunidade de ler sobre o que acontecia no resto do mundo e de aprender sobre o comunismo e o sindicalismo. De modo geral, portanto, temos em Peões a idéia de que sair do nordeste e entrar numa fábrica em São Paulo possibilitou que aqueles metalúrgicos amadurecessem politicamente de uma maneira que seria impossível no contexto nordestino. A consciência política surge como fruto das condições específicas da cidade grande e da atividade política desenvolvida no chão de fábrica. Pertencer ao proletariado é um caminho que aparece como necessário para o amadurecimento político de grande parte dos indivíduos entrevistados.

Em São Paulo e em São Bernardo diversos entrevistados, ao serem questionados sobre como começaram a participar das greves, irão, naturalmente, como decorrência da pergunta, contar sobre seu progressivo interesse pela política. Nice diz que começou a participar das greves "sabendo o que estava fazendo" apenas em 1979, o que nos dá a impressão de que antes ela já trabalhava e militava mas que não tinha consciência completa do que era a luta política. Tê diz que começou a trabalhar como metalúrgica depois da greve de 1979 mas que já começara a sentir um "calorzinho" antes ao acompanhar o irmão metalúrgico envolvido com a militância. Antônio conta que aos poucos foi "tomando o gostinho" pela militância. De modo geral a sensação durante as entrevistas é a de que os militantes foram nascendo 
e se desenvolvendo com os acontecimentos de 1979 e 1980. A exceção talvez seja Januário, que conta que desde muito cedo em sua vida já estava envolvido na "luta", seja na Igreja, nos movimentos de bairro, no movimento estudantil, etc. Este entrevistado se diferencia dos demais, pois parece que sempre esteve e ainda está envolvido com a militância. Os demais entrevistados nos parecem ter passado por um processo de progressiva tomada consciência política enquanto o próprio sindicalismo crescia no ABC. É um processo que em entrevistas e em Entreatos Lula diz ter ocorrido com ele mesmo, pois ele só teria amadurecido politicamente na medida em que o próprio sindicalismo ganhava força. Como já dissemos, em diversas ocasiões Lula tenta passar a imagem de que, antes de ser um líder extraordinário nato, ele foi fruto do processo de tomada de consciência de toda uma categoria.

No entanto, a progressiva tomada de consciência é um processo que em Peões parece ter ocorrido aos anônimos entrevistados, e não ao próprio Lula. A utilização das imagens dos filmes anteriores (Greve!, ABC da Greve e Linha de Montagem) nos causam a sensação de um Lula já pronto, plenamente no controle do que estava fazendo, como se houvesse tido desde sempre a consciência política necessária para organizar as grandes greves que balançaram alguns alicerces da ditadura militar. Ou seja, o contraste entre as entrevistas que nos dizem sobre a progressiva tomada de consciência dos peões e as poderosas imagens de Lula em seus discursos colaboram para reforçar o aspecto extraordinário do dirigente sindical. Em contraste com os peões entrevistados, que parecem ter aprendido a militar, Lula parecer ter nascido pronto para a liderança e o combate.

As primeiras imagens de Lula aparecem por volta dos onze minutos de filme e se referem à primeira greve de 1979. A primeira legenda informa que "Lula lidera cerca de 140 mil grevistas". Lula aparece carregado pela multidão reunida em Assembléia. A segunda legenda nos informa que a greve foi declarada ilegal e que a diretoria do sindicato é afastada. Vemos Lula falar à multidão sobre a importância do trabalho nos bairros para 
| 16 |

Peões: Lula e a nostalgia da classe operária

a manutenção da greve. A terceira legenda informa sobre a trégua de quarenta e cinco dias e sobre o fim da trégua e a conseqüente volta ao trabalho sem ganhos para os trabalhadores. As imagens mostram Lula pedindo a volta ao trabalho e assumindo o compromisso de decretar a greve outra vez caso o acordo feito com os patrões seja descumprido. A quarta legenda fala sobre a criação do fundo de greve e a subseqüente greve de quarenta e um dias. Lula fala à multidão reunida em assembléia sobre a importância da luta para fazer avançar as conquistas dos trabalhadores. A quinta legenda informa sobre a repressão, o fim da greve e o despontar de Lula como nome nacional. Vemos imagens da repressão policial. A sexta legenda informa sobre a criação do PT em 1981. É seguida de outra legenda que fala sobre a eminente vitória à presidência da República de Lula em 2002. As imagens nos mostram uma passeata eleitoral com o candidato Lula em São Bernardo do Campo. Certamente há aí a ideia de um tempo passando, de uma trajetória de começa no $\mathrm{ABC}$ e termina na eminência da conquista do Palácio do Planalto. No entanto, as cenas de Lula em São Bernardo já nos remetem a um líder pronto, cujo aspecto extraordinário não se refere a um processo gradual e temporal mas a um traço da personalidade do dirigente.

Teremos ainda outras imagens de Lula retiradas dos filmes anteriores ao longo de Peões. Aos vinte e dois minutos um Lula hesitante fala à multidão em assembléia. Aos trinte e oito minutos vemos o dirigente numa assembléia no sindicato pedindo aos trabalhadores que mantenham a greve "até a vitória final" mesmo que ele, Lula, seja preso. Mais à frente veremos a cena, também no sindicato, em que Lula pede que os operários se manifestem livremente rejeitando a continuidade da diretoria caso entendam que ela não tenha defendido adequadamente seus interesses. No final do filme, vemos a última imagem de Lula, chamando uma greve e pedindo que as pessoas reunidas em assembléia levantem a mão para mostrar ao país que a categoria dos metalúrgicos como um todo quer a paralização do trabalho. 
Estas imagens, junto às legendas que as acompanham, contextualizam os acontecimentos de São Bernardo do Campo e Diadema e também nos fazem visualizar a fonte da qual as imagens dos anônimos foram retiradas. Muitos dos espectadores de hoje eram jovens demais ou ainda não nascidos para terem lembrança daqueles acontecimentos. Coutinho aproveita a disponibilidade das imagens de colegas cineastas e insere nelas algumas legendas como forma de contextualização para o espectador atual. As imagens permitem assim que o espectador tenha uma breve noção do que se passou. É claro que a contextualização não é algo que ocorre de maneira "neutra". Em primeiro lugar porque os filmes anteriores, de modo geral, constroem uma imagem muito positiva da liderança de Lula. Ao usar estes filmes, Coutinho acaba usando sua positividade em relação ao dirigente. Em segundo lugar porque Eduardo Coutinho escolhe, dentre as imagens possíveis, justamente aquelas na qual vemos Lula em atos de liderança e mobilização. A própria contextualização, portanto, é favorável ao então candidato a presidente, e o que se contextualiza, na verdade, é antes a enorme expressão do dirigente sindical do que os acontecimentos de 1979 e 1980.

Além do uso das imagens como contextualização do momento histórico (e do aspecto extraordinário do dirigente sindical Lula) e como fonte de reconstrução e interpretação histórica, temos também em Peões a ideia, recorrente em um tipo de cinema documental, de se mostrar as imagens filmadas para as pessoas que delas participaram. Este procedimento já havia sido utilizado e colocado em cena por Eduardo Coutinho em Cabra Marcado Para Morrer e é um procedimento bastante utilizado em documentários de tipo interativo. O cineasta filma determinados indivíduos numa comunidade e depois passa o filme para os próprios indivíduos e para a comunidade. Trata-se de uma ideia que se popularizou a partir do cinema de Jean Rouch e Edgar Morin em Crônica de um Verão. Neste filme vemos as imagens do próprio documentário sendo projetado para aqueles que participaram dele, bem como a reação das pessoas filmadas 
| 18 |

Peões: Lula e a nostalgia da classe operária

à projeção. Jean Rouch também projetava os filmes feitos nas colônias francesas da África para os que deles haviam participado, ainda que não tenha inserido estas projeções como elemento dos filmes. Em Peões trata-se de um procedimento parecido, com a diferença de que não é o próprio cineasta diretor de seu filme que o projeta (não foi Coutinho quem dirigiu os filmes que ele passa para seus entrevistados) e com a diferença de que os participantes do filme não estão reunidos no mesmo tempo e lugar para se observarem nas imagens. Cada entrevistado irá se ver de maneira isolada em relação aos outros entrevistados. Além disso, há entre o filme original e a projeção uma diferença temporal de vinte anos que, como em Cabra Marcado Para Morrer, dá uma conotação de "resgate histórico" aos filmes projetados. No entanto, o que nós, espectadores, vamos ver, não são apenas, e nem predominantemente, as imagens dos anônimos, e sim as de Lula. As imagens dos anônimos se vendo nos filmes do passado aparecem, mas o que aparece sobretudo ao espectador são os discursos do dirigente sindical incitando uma greve ou pedindo a volta ao trabalho. Pelo fato de que a nós nos é dado a ver sobretudo as imagens de liderança de Lula retiradas dos filmes anteriores, o que ocorre então, como já sugerimos, é um contraste entre o processo progressivo de tomada de consciência ao qual os entrevistados se referem e as imagens de Lula como um líder nato que tem como tarefa levar a classe operária a um novo patamar de conscientização. As imagens que vemos de Lula em Peões reforçam, portanto, o aspecto extraordinário do dirigente em oposição aos anônimos entrevistados.

A ideia de um Lula que nasceu "pronto" e como alguém extraordinário é reforçada também pelos próprios entrevistados. Para Joaquim, Lula é um "segundo pai", "esse homem que nós tanto admira hoje". Januário, como já citado, diz que "Lula é o cara". Tê diz que gosta muito do Lula, que considera um dos homens mais inteligentes que ela já conheceu, e que é o Lula que está chegando a Presidência da República, e não o PT. Luiza diz que Lula é uma grande pessoa, um grande companheiro, a que a mãe dele "deve estar com muito orgulho de ter parido um filho 
tão lindo". Zélia, servente do sindicato, diz que sua relação com Lula sempre foi muito boa e que Lula para ela é como um pai, um irmão, "como tudo". Ela sonha com o dia em que irá fazer e servir café para o Lula no Palácio do Planalto, como presidente. Elza diz que adora a parte do hino nacional que diz que "um filho teu não foge à luta", que acha bonito um homem lutar, e que Lula representa essa frase do hino. Segundo ela, Lula é aquele não foge à luta. Geraldo, o último entrevistado, diz que Lula foi um herói na época das greves. Naturalmente, essas falas não surgem, na maioria dos casos, espontaneamente, mas são incentivadas pelo próprio Coutinho, que pergunta aos entrevistados o que eles acham do Lula e pedem para que eles contem como era sua relação com o dirigente. Além do incentivo de Coutinho, há o incentivo do próprio momento histórico, com a empolgação da iminência da chegada de Lula à Presidência da República, que ajuda os entrevistados a se entusiasmarem com o ex-sindicalista. É interessante notar, portanto, que um filme que se define como uma obra que tem como objetivo dar a palavra aos anônimos refira-se com tanta insistência ao então candidato a presidente. Lula mal aparece, mas sentimos que é ele o grande personagem aqui, resgatado pelas histórias das pessoas que o conheceram quando ele era dirigente sindical. A meu ver, isso colabora para um aspecto de indeterminação do filme, e para uma sensação de que o estilo até então repetido por Coutinho começa a dar indícios de esgotamento. Peões não é um filme no qual os anônimos parecem dotados daquela graça e singularidade que sentimos em outros filmes do cineasta, como Santo Forte e Edifício Master. Talvez Coutinho não se detenha sobre os anônimos tempo suficiente, talvez suas histórias não sejam suficientemente boas, ou talvez o sentido da entrevista de Coutinho seja abalado quando o cineasta pede aos anônimos que falem sobre uma outra pessoa que está em vias de se tornar Presidente da República. Quando os anônimos começam a se referir a uma celebridade, algo da força e do interesse dos anônimos se perde, e é transferida para a celebridade (no caso Lula). Ao colocar os anônimos para falar sobre outra pessoa, 
| 20 |

Peões: Lula e a nostalgia da classe operária

o espectador tende a sentir que a fala do entrevistado não tem interesse em si mesma, mas pelas informações que ela pode nos fornecer sobre a vida da celebridade. A opção de Coutinho em estimular a fala sobre a celebridade enfraquece seu estilo de documentário, na medida em que o interesse pela vida do anônimo diminui. Diante de uma situação tão extraordinária como a de Lula, ex-torneiro mecânico prestes a chegar à Presidência da República, porque deveria o espectador interessarse pelo banal que aparece na fala dos entrevistados?

Por outro lado, sentimos que Coutinho perdeu a oportunidade de explorar de modo mais intenso seus entrevistados. Porque ouvimos tão pouco de Djalma, dirigente importante na época, que aparece nos três filmes anteriores citado, que falava tão bem em seus discursos, tinha pose de galã e ainda sabia cantar? Provavelmente este anônimo deve ter diversas histórias para contar que não foram exploradas. Porque não vemos as diversas mulheres entrevistadas serem questionadas sobre a participação feminina nas greves e sobre como elas eram recebidas no seio de um ambiente tradicionalmente tão masculino? Como o evangélico Henok ou João Chapéu, casado com uma evangélica, conciliam o comunismo (que o segundo diz professar) ou a atividade sindical com a religião? Como Antônio, que fez 1056 horas extras com apenas três dias de folga durante o ano de 1975, concilia seu stakhanovismo com a luta do sindicato ao qual se associava? Porque a inclusão de Januário no filme, um exmetalúrgico que tem uma trajetória de vida tão diferente dos demais entrevistados? Porque o cineasta não dialoga e explora a entrevista com Conceição, que teve problemas de saúde pelo esforço repetitivo e ainda assim sente sua pensão como uma dádiva da Volks e não como um direito seu? O ato de evitar o diálogo e contestar o entrevistado, por exemplo no caso de Conceição a quem poderia ser dito que a pensão que recebe não tem nada a ver com a generosidade da empresa, ilustra a afirmação de JeanClaude Bernardet de que não se dialoga com entrevistado pobre (2003: 294). Tudo que o pobre diz parece ser importante e o entrevistador não se comporta como um verdadeiro interlocutor 
com receio de que, se contestar o entrevistado, estará colaborando com os mecanismos de opressão de classe (2003: 295). Acredito que um dos problemas de Peões ocorre justamente porque há a sensação de que nem tudo que o entrevistado diz é tão interessante e comovedor. As falas estão muito mais próximas do banal do que do extraordinário, quando o grande mérito de Coutinho em filmes anteriores tinha sido justamente articular estas duas características no anônimo entrevistado. Como estão muito mais próximas do banal, a menção a Lula aparece como fator de criação de um contraste, exacerbando o aspecto banal do entrevistado e aspecto extraordinário de Lula.

As questões possíveis e não realizadas que citei acima me parecem questões bastante prováveis de serem perguntadas aos entrevistados. Elas possibilitariam uma exploração melhor daquilo que pode ser interessante no personagem anônimo. Pode-se dizer que as respostas às questões citadas têm interesse numa relação de alteridade entre o espectador e o objeto do filme. O cinema de Eduardo Coutinho tem como espectador ideal o "outro" em relação ao entrevistado, de modo que este transmita uma experiência de vida e um conhecimento sobre sua situação que aquele não tem. Em filmes como Santo Forte e Edifício Master sentimos que o anônimo é melhor explorado pela entrevista: há mais tempo para que ele fale e as histórias parecem mais interessantes. No encarte que acompanha o DVD de Peões Coutinho diz que neste filme teve que participar da pesquisa para a realização do filme, o que ele não gosta e não costuma fazer. Coutinho tem uma equipe de confiança que encontra os anônimos interessantes para serem entrevistados. O cineasta só aparece na frente do entrevistado e só o conhece quando vai efetivamente gravar a cena. Isso faz com que o entrevistado conte suas histórias para Coutinho como se fosse a primeira vez, o que as torna mais interessantes. Não é possível determinar com exatidão o quanto a mudança no procedimento habitual influenciou a estética do filme, mas o que efetivamente ocorre é que em Peões as coisas se passam de modo mais monótono do que em outros filmes do cineasta. 
| 22 |

Peões: Lula e a nostalgia da classe operária

O que aparece, sobretudo, entremeado nas falas dos entrevistados, é a nostalgia, como já dissemos, daquele tempo que passou. Um tempo que às vezes aparece como romântico, como mais emocionante, onde os entrevistados eram jovens e tinham ideais de transformação social. Isso aparece na fala de Tê, cujos olhos até brilham quando ela fala daquele tempo. Coutinho pergunta: “Como você viveu a greve de 1980" e ela responde, como se falasse de um grande amor: "Eu vivi essa greve intensamente...". Mais para frente, lamenta o tempo passado: "É uma pena que eu não tenha vinte e três anos... Se eu tivesse vinte e três anos... Sabe, eu acho que eu bati em retirada cedo (se referindo ao fato de que largou muito cedo o emprego de metalúrgica), eu poderia ter lutado mais, não sei o que aconteceu..."

De modo geral há nas entrevistas essa sensação romântica da luta. Socorro achava bonito ver as greves pela televisão, até que em 1981 resolveu sair do Ceará e ir se empregar nas fábricas onde as pessoas lutavam. Avestil diz que gosta de contar as histórias das greves para seus filhos e que espera que eles sintam orgulho da luta de seu pai. João Chapéu diz que acha a coisa mais linda quando se fala em sindicalismo. Nice, apesar de sentir uma dor por não ter participado da criação dos filhos tanto quanto gostaria em virtude do movimento sindical, demonstra orgulho por ter participado de um momento importante na história do país e por ter dado sua colaboração para a redemocratização da sociedade. Elza, como já falamos, diz que acha bonito uma pessoa lutar e por isso gosta da frase do hino "verás que um filho teu não foge à luta". Zélia, servente do sindicato, diz que sente orgulho por ter salvado o filme Linha de Montagem da apreensão pela polícia após exibição no sindicato. Notadamente, de novo, estas respostas não surgem espontaneamente. Coutinho faz perguntas para que os entrevistados expressem seu orgulho por terem participado das lutas. Como comentamos em capítulo anterior, o cineasta precisa construir um tema para seu filme, e incentivar os entrevistados a expressar orgulho em relação ao passado de luta 
colabora para a construção do tema de Peões. Nesse sentido, Peões é nostálgico: o passado de lutas é fonte de saudade, admiração, e o rememorar deste tempo vem associado a um sentimento positivo por parte dos entrevistados.

A nostalgia pela luta se junta à nostalgia pela função e pela identidade operária. Da mesma forma que há um sentimento positivo em relação a ter participado das greves, há um sentimento positivo em relação a ter pertencido à classe operária. A exceção é o último entrevistado, Geraldo, que continua peão mas que agora vive de bicos e trabalhos temporários. Ele quer que seus filhos estudem e não passem o sofrimento que ele passou como peão. Sua fala no entanto aparece um tanto isolada no conjunto de entrevistas, e contrasta com aquela em que pai e filho se apresentam como peões de fábrica e dizem ter orgulho da profissão. Antônio, o pai, dirá: “É desmérito ser peão? Não. É orgulho". Depois de tantas entrevistas em que se valoriza a identidade do peão, é até surpreendente para o espectador ouvir do último entrevistado, Geraldo, uma fala de teor mais pessimista em relação à sua profissão. No conjunto, no entanto, acredito que a fala de Geraldo não invalida o sentimento geral do filme de valorização da identidade operária. Mesmo porque o que parece é que Geraldo reclama não exatamente de ser peão, mas das dificuldades de arrumar emprego de metalúrgico (soldador) na atualidade. Além disso, Coutinho de alguma forma tenta recuperar a valorização da identidade operária apesar do tom pessimista de Geraldo ao perguntar se ele tem orgulho de ser alguém que faz um trabalho bem feito (pergunta um tanto aleatória e deslocada pois nenhum argumento ouvimos sobre a qualidade do trabalho daquele entrevistado). A resposta de Geraldo é positiva: "Sim, eu tenho, eu sou um profissional há muitos anos e tenho orgulho de fazer isso aí". É a deixa para Coutinho insistir no aspecto positivo de ser metalúrgico: "Nesse sentido você às vezes tem saudade do tempo da fábrica". Geraldo, educado, concorda com seu interlocutor: "Sim, às vezes eu tenho, (mesmo) com todo o sofrimento da época, eu tenho saudade". 
| 24 |

Peões: Lula e a nostalgia da classe operária

Em relação aos demais entrevistados, é possível sustentar que paira sem hesitações a valorização da identidade operária. João Chapéu é taxista há vinte e um anos mas diz que não é um verdadeiro taxista, apenas quebra o galho. Tê diz ter saído muito cedo da profissão de metalúrgica mas que, mesmo depois de ter sido doméstica e ter tido outras profissões, ainda tem muita identidade com a categoria de origem. Ela diz que continua sendo metalúrgica de coração. Muitos foram demitidos depois das greves dos anos 80 e a maioria acabou mudando de profissão, como Januário, que virou fotógrafo, Bitu, que virou sacoleiro, e Miguel, que montou um salão de forró e depois foi cobrador de ônibus. Apenas Januário parece ter tido controle sobre o que desejou fazer depois de sair da fábrica. Bitu reclama da quantidade de viagens que fazia ao Paraguai para sustentar sua família e Miguel não gostava de ser cobrador pois considera uma profissão perigosa. Parece-nos que, depois das greves, foram poucos os que continuaram metalúrgicos. No entanto, incentivados por Coutinho, eles falam daquele tempo como se ainda o fossem. De modo geral, a sensação durante o filme é efetivamente aquela expressa por Tê: ainda parecem metalúrgicos de coração. Isso é interessante porque contrasta com as falas anti-nostálgicas de Lula em Entreatos e porque é expressão não apenas de um tempo que passou para os entrevistados mas também de um tempo que passou no que se refere ao trabalho fabril. Como bem lembra Januário, com a reestruturação produtiva, existem postos de trabalho nas montadoras que simplesmente não existem mais. Januário diz ter entrado recentemente numa fábrica da Volks com Lula e ter comentado: "Imagina fazer uma greve com esse povo?". Ele mesmo responde: "Que povo? Só computador...". Há em Peões portanto não apenas uma nostalgia no que refere à identidade operária que os ex-metalúrgicos dizem não ter perdido mas também em relação a um passado onde a classe proletária podia ser localizada e definida com mais facilidade.

A nostalgia de Peões pelo proletariado e pela luta de classes é a nostalgia de um tempo em que as ideias revolucionárias reverberavam no país e pareciam ter inclusive alguma eficácia 
prática. É nos anos 80 que o desmantelamento da URSS, a queda do Muro de Berlin e o Neoliberalismo, junto com a restruturação produtiva e o fim do proletariado tradicional, decretam um fim prematuro das ideias revolucionárias e o início do que foi denominado "pensamento único". Peões, portanto, é um filme nostálgico de toda uma sociedade e de uma forma de pensamento que parecem ter desaparecido nos anos 80 , o que inclui a nostalgia por aquele Lula aguerrido, de barba desgrenhada e hirsuta, que se recusava a participar da política tradicional e empunhava com orgulho a pecha de sindicalista.

\section{Bibliografia}

BERNARDET, Jean-Claude. Cineastas e imagens do povo. São Paulo: Companhia das Letras, 2003.

LINS, Consuelo. O Documentário de Eduardo Coutinho. Rio de Janeiro: Jorge Zahar, 2004.

RIDENTI, Marcelo. Em Busca do Povo Brasileiro. Rio de Janeiro: Record, 2000. 